\title{
Regulamentar faz diferença? O caso da evidenciação ambiental ${ }^{\star}$
}

\section{Can regulation make a difference? The case of environmental disclosure}

\author{
Alex Mussoi Ribeiro \\ Doutorando do Programa de Pós-Graduação do Departamento de Contabilidade e Atuária da Faculdade de Economia, Administração e \\ Contabilidade da Universidade de São Paulo. \\ E-mail: amr@usp.br
}

Hans Michael Van Bellen

Professor Doutor do Departamento de Engenharia do Conhecimento do Centro Tecnológico da Universidade Federal de Santa Catarina. E-mail: hansmichael@cse.ufsc.br

Luiz Nelson Guedes de Carvalho

Professor Doutor do Departamento de Contabilidade e Atuária da Faculdade de Economia, Administração e Contabilidade da Universidade de São Paulo.

E-mail: Inelson@usp.br

Recebido em 14.09.2010 - Aceito em 11.01.2011 - $2^{a}$. versão aceita em 27.01.2011

\section{RESUMO}

Baseado na discussão entre tornar o disclosure ambiental obrigatório ou não, o objetivo desta pesquisa foi verificar se as práticas de evidenciação ambiental das companhias analisadas reagem aos distintos estímulos regulatórios de seus países de origem. A resposta desta pergunta é útil no sentido de determinar a eficácia da introdução de mecanismos regulatórios nas práticas de evidenciação ambiental. Uma vez que o disclosure ambiental é, predominantemente, voluntário as companhias podem simplesmente suplantar a regulação, tornando-a sem sentido. Para o desenho metodológico, optou-se por uma abordagem descritiva de cunho predominantemente quantitativo. A amostra foi selecionada de empresas do setor de petróleo e gás natural de quatro países com similaridades culturais: os Estados Unidos, o Canadá, a Inglaterra e a Austrália. Os dados analisados foram coletados nos relatórios anuais no ano de 2007. Para classificar os dados ambientais utilizou-se uma escala adaptada de dois trabalhos consagrados no meio da evidenciação ambiental, o estudo de Clarkson et al. (2008) e o de Wiseman (1982). O teste estatístico (teste H) comprovou que existem diferenças significativas entre os níveis de evidenciação ambiental das companhias da amostra pertencentes aos países mais regulados em comparação com os menos regulados e essas diferenças só foram significativas nos itens de divulgação obrigatória, o que comprova que o disclosure ambiental das companhias reage aos estímulos regulatórios de seus países.

Palavras-chave: Evidenciação Ambiental. Meio Ambiente. Contabilidade. Regulamentação.

\section{ABSTRACT}

Based on different opinions concerning the need for mandatory environmental disclosure, the main purpose of this research was to verify whether or not the company's environmental reporting practices 
react to different regulatory stimuli. The answer to this question is useful to evaluate the effectiveness of the introduction of regulatory mechanisms in environmental disclosure practices. Since environmental disclosure is mainly voluntary, companies can simply override regulation, making it pointless. The method of research chosen was of a descriptive and predominantly quantitative nature. The companies selected as samples were from the oil and natural gas sectors from four different countries who share cultural similarities, such as the United States, Canada, England and Australia. The environmental information was collected from annual reports year ended 2007. In order to classify the environmental data used, a suitable comparative analysis of two consecrated works was used - the study of Clarkson et al. (2008) and the study of Wiseman (1982). The statistical tests proved that there are significant differences between the regulated and the unregulated countries, and the greatest differences were found when mandatory disclosure was utilized, thus proving that countries can indeed react to different regulatory stimuli.

Keywords: Environmental Disclosure. Accounting. Mandatory. Regulation.

\section{INTRODUÇÃO}

À medida que os problemas ambientais se agravam, a sociedade passa a se preocupar mais com a degradação do meio ambiente. Essa preocupação, conhecida como consciência ecológica, pode se manifestar de forma introspectiva, mediante ajustes de conduta individual, e de forma coletiva, por meio de reivindicações para práticas globais ambientalmente corretas. Independentemente da forma escolhida pelos atores sociais, as empresas são consideradas os alvos principais das exigências ambientalistas. As companhias podem ser afetadas tanto de forma introspectiva (direcionamento de investimentos, consumo de mercadorias e disponibilidade de mão de obra) quanto de forma coletiva (manifestações, propagandas negativas e processos públicos). Para as duas formas de pressão social, a resposta das companhias deverá ser dada sob a forma de accountability ambiental. De acordo com Gray, Owen e Adams (1996), o termo accountability ambiental é utilizado para designar a responsabilidade de prestação de contas sobre a conduta ambiental de determinada organização. Essa prestação de contas é realizada por meio da evidenciação ambiental corporativa - EAC que, segundo Nyquist (2003), serve para mensurar e avaliar os impactos ambientais das atividades econômicas e, assim, suprir a demanda de informações ambientais de diversos grupos de stakeholders.

Segundo Gray e Bebbington (2001), desde o seu começo, em meados da década de 70 , as práticas de EAC vêm se desenvolvendo de forma expressiva, principalmente nos últimos anos e no meio das grandes corporações. Apesar da forte ascensão da EAC nas últimas décadas, ainda existem muitas críticas sobre a forma e o conteúdo ambiental divulgado pelas corporações. As principais falhas detectadas em trabalhos anteriores são referentes à falta de uniformidade ou comparabilidade entre as empresas, a ausência de profundidade e objetividade das informações ambientais, a inexistência de uma continuidade de divulgação (a maioria das empresas não publicam relatórios ambientais regularmente), a constância apenas na divulgação de informações positivas e a falta de credibilidade das informações ambientais divulgadas, uma vez que elas não passam por auditoria externa (COSTA; MARION, 2007; DEEGAN; GORDON, 1996; DEEGAN; RANKIN, 1996; GRAY; BEBBINGTON, 2001; SKILLIUS; WENNBERG, 1998).

Alguns autores, como Gray e Bebbington (2001), Gray, Owen e Adams (1996), Adams (2004), Gallhofer e Haslam (1997), Freedman e Wasley (1990), Freedman e 
Stagliano (2007), Beets e Souther (1999), Harte e Owen (1991) e Holgaard e Jorgensen (2005), sugerem que uma maneira de resolver a maioria desses problemas seria acabar com a natureza voluntária da evidenciação ambiental, ou seja, torná-la regulamentada. Por outro lado, pesquisadores, como Gunningham, Grabosky e Sinclair (1998), Larrinaga et al. (2002), Zerk (2006), Holland e Foo (2003), Maunders e Burrit (1991), Cooper (1992) e Power (1991), defendem que regulamentar o disclosure ambiental seria um retrocesso na prestação de contas com essa finalidade, isso porque, a regulamentação traria uma série de problemas como foco excessivo na conformidade, perda de motivação na busca por valores fundamentais, perda de inovação e criatividade e diminuição da competitividade, o que prejudicaria o disclosure ambiental de maneira geral.

Apesar de existirem diversos trabalhos que criticam ou defendem a regulamentação do disclosure ambiental, poucos deles se preocuparam em verificar empiricamente o efeito dos regulamentos sobre tais práticas. Isso revela certa incoerência, pois, antes de recomendar ou censurar a regulamentação, é sensato saber se ela gera algum efeito (seja positivo ou negativo) em um ambiente em que predomina o disclosure voluntá- rio (BUHR, 2007; GRAY; BEBBINGTON, 2001). Com o objetivo de preencher essa lacuna, elaborou-se a seguinte questão de pesquisa: O nível de disclosure ambiental está relacionado com o marco regulatório do país sede da empresa? A finalidade desta pesquisa é investigar se as práticas de evidenciação ambiental das companhias analisadas reagem aos estímulos regulatórios de seus países de origem ou se elas suplantam tais estímulos mediante evidenciação voluntária. Para isso foi necessário atingir os seguintes objetivos específicos: (1) medir o nível de evidenciação das companhias analisadas; (2) verificar se existem diferenças entre os marco regulatórios dos países analisados e (3) comparar o nível de disclosure obtido com base nos mecanismos regulatórios de cada país. De acordo com Lopes (2002, p. 49), apesar de a investigação empírica sobre o impacto da regulamentação na evidenciação ser bastante complicada devido ao grande número de variáveis que podem influenciar os resultados, os estudos dessa natureza têm uma contribuição fora do restrito contexto empresarial, ou seja, mais ampla para a sociedade. Este trabalho estrutura-se em seis partes: (1) introdução; (2) hipóteses; (3) referencial teórico; (4) metodologia; (5) apresentação dos resultados e (6) considerações finais.

\section{HIPÓTESES}

Como foi descrito anteriormente, o objetivo principal deste trabalho é o de investigar se as companhias reagem aos estímulos regulatórios de evidenciação ambiental de seus países de origem. Devido, principalmente, ao aumento, nos últimos anos, da quantidade de legislação que regula as práticas de evidenciação ambiental (MEDLEY, 1997), é factível aceitar que as companhias reagem aos estímulos regulatórios, caso contrário essa tendência não seria observada, uma vez que se trataria apenas de desperdício de dinheiro e esforços públicos. Com base nisso e na verificação da existência de diferenças entre os marcos regulatórios dos países analisados, foi elaborada a seguinte hipótese:

H1. Existem diferenças significativas entre os níveis de evidenciação ambiental das empresas pertencentes aos países analisados.

Por outro lado, de acordo com a teoria do stakeholder, uma vez que as companhias, por motivos éticos, divulgam as informações demandadas por seus grupos 
de interesse, não existe a necessidade de regulamentar as práticas de evidenciação ambiental. Se essa teoria estiver correta e levando em consideração que a demanda de informações ambientais dos stakeholders de países com similaridades culturais e institucionais não é muito volátil, não devem existir diferenças significativas entre os níveis de divulgação ambiental das companhias que possuem sede em países com diferentes regulamentações para essas práticas. Por esse motivo é es- perado que, se as diferenças forem atribuíveis apenas aos estilos regulatórios, as informações de evidenciação voluntária não devem apresentar diferenças significativas no meio das companhias analisadas. Sendo assim, a segunda hipótese testada neste trabalho é:

$\mathrm{H} 2$. As diferenças significativas ocorrem apenas nos itens de evidenciação em que as companhias são regulamentadas, nos demais itens de evidenciação voluntária tais diferenças não devem ser significativas.

\section{REFERENCIAL TEÓRICO}

$\mathrm{Na}$ base teórica deste artigo, foram tratados alguns assuntos relevantes para o entendimento do processo de evidenciação ambiental voluntário e regulamentado. Tais aspectos passam pelos fatores determinantes da evidenciação ambiental voluntária, pelos trabalhos que já estudaram teórica e empiricamente a regulamentação do disclosure ambiental e pelas diferenças existentes entre padronizar e regulamentar tais práticas de evidenciação.

\subsection{Fatores determinantes da evidenciação ambiental corporativa}

Segundo Gray e Bebbington (2001), a maioria das informações ambientais divulgadas no meio corporativo é de natureza voluntária e não auditada. Por isso, o entendimento dos fatores determinantes por trás das práticas de EAC tornou-se relevante na busca de um aprimoramento desse campo de pesquisa. $\mathrm{Di}$ versos estudos apontam para a existência de alguns fatores que impactam, diretamente, na evidenciação ambiental corporativa. Entre os mais explorados estão: o tamanho da companhia (CORMIER; GORDON, 2001; CORMIER; MAGNAN; VELTHOVEN, 2005; GAO et al., 2005; GRAY et al., 2001; HACKSTON; MILNE, 1996; TROTMAN; BRADLEY, 1981); o seu setor de atuação (GAO; HERAVI; XIAO, 2005; GRAY et al., 2001; GUTHRIE;
CUGANESAN; WARD, 2008; HACKSTON; MILNE, 1996; HALME; HUSE, 1997); o seu país sede (GAMBLE et al., 1996; HALME; HUSE, 1997); a sua lucratividade (GRAY et al., 2001) e a forma pela qual ela se relaciona com seus stakeholders (BOESSO; KUMAR, 2007; ISLAM; DEEGAN, 2008; TROTMAN; BRADLEY, 1981). No Brasil, três trabalhos destacam-se sobre o assunto: o de Murcia, Santos e Souza (2009); o de Rover et al. (2009) e o de Braga e Salotti (2008). Nos três estudos, ficou constatado que o tamanho da companhia é fator relevante para explicar as práticas de EAC. O de Rover et al. (2009) e o de Murcia, Santos e Souza (2009), também, acharam a inclusão no índice de sustentabilidade da Bovespa como um fator determinante e o de Braga e Salotti (2008) ressalta a importância da riqueza criada e da natureza da atividade.

$\mathrm{O}$ que se pode concluir com base nesses estudos é que, apesar de existirem diversos fatores endógenos e exógenos, identificáveis ou não, que podem afetar a EAC, três fatores se destacam dos demais: o tamanho da companhia (normalmente representado pelo faturamento ou patrimônio líquido); o seu setor de atuação (ou natureza da atividade) e o seu país sede (ou influências culturais). Essas variáveis foram consideradas influentes em todos os trabalhos que testaram o seu papel sobre o disclosure ambiental. 


\subsection{Trabalhos que analisaram}

aspectos regulatórios da evidenciação ambiental

Os estudos relacionados com a análise do disclosure ambiental regulamentado podem ser classificados em três tipos: (1) estudos comparativos internacionais que tratam dos marcos regulatórios e das práticas de disclosure ambiental; (2) estudos que analisam apenas os marcos regulatórios e (3) estudos que analisam as consequências da implantação de determinada norma na evidenciação ambiental. Nos trabalhos comparativos internacionais, destacam-se as pesquisas de Roberts (1991), Gamble et al., (1996), Buhr e Freedman (1996), Halme e Huse (1997), Adams, Hill e Roberts (1998), Holland e Foo (2003), Jorgensen e Soderstrom (2007) e Aerts et al. (2006). Em todos esses artigos foram realizadas comparações nos níveis de evidenciação em companhias de diferentes países, com destaque para as pesquisas de Gamble et al. (1996), Jorgensen e Soderstrom (2007) e Buhr e Freedman (1996) que, também, realizaram um levantamento incipiente nos marcos regulatórios de EAC dos países envolvidos.

Já as pesquisas sobre marcos regulatórios, caracterizam-se por tratarem, exclusivamente, da análise das leis que regem as práticas de EAC. Entre esses estudos estão os da KPMG (2005), KPMG e UNEP (2006), IIIEE (2002), Skillius e Wennberg (1998), Nyquist (2003), Repetto, Macskimming e Isunza (2002) e Alciatore, Dee e Easton (2004). Todas essas pesquisas analisam de maneira aprofundada as estratégias regulatórias adotadas por diferentes países na regulação das práticas de EAC. Alguns aspectos analisados por tais trabalhos são: o conteúdo da norma, o seu poder de enforcement e a forma em que eles foram outorgados. Por fim, os trabalhos que analisam as consequências da implantação de determinada norma na evidenciação ambiental, procuraram verificar empiricamente os efeitos positivos e negativos de tais práticas (COWAN; GADENNE, 2005; FROST, 2007; LARRINA-
GA et al. 2002). Os resultados apresentados por eles foram diversificados, enquanto, em alguns países, a regulação foi favorável (Noruega, Suécia, Holanda e Austrália) em outro ela foi desfavorável (Espanha).

\subsection{Regulamentação $\mathrm{x}$ padronização}

Apesar de existir certa coincidência na finalidade dos padrões e dos regulamentos, existem diferenças conceituais básicas entre padronizar e obrigar a evidenciação de informações corporativas. De acordo com Scott (2003), a padronização é a regulação da decisão de produzir informações externas em uma companhia por uma autoridade central. Embora o autor use o termo regulação para definir o conceito de padronização, nem sempre ela ocorre de maneira obrigatória. No caso das práticas de evidenciação ambiental, existem diversos padrões voluntários que servem de guia para divulgar informações ambientais e, mesmo assim, compartilham do conceito introduzido pelo autor como, por exemplo, os mecanismos autorregulatórios, nos quais o Global Reporting Initiative (GRI) é a grande bandeira. Por outro lado, regulamentar não necessariamente significa padronizar a divulgação de informações ambientais. A evidenciação ambiental poderá ser imposta por instrumento regulatório, mas não de forma padronizada.

A principal diferença que distingue a padronização da obrigatoriedade de divulgar informações é a finalidade de sua implantação. De acordo com Besanko (1987), existe uma grande diferença entre a regulamentação da performance e a regulamentação do processo. $\mathrm{O}$ autor argumenta que, enquanto a regulamentação do desempenho é orientada ao objetivo, a do processo é voltada às etapas para atingi-lo. Entender essa diferença é crucial para compreender a distinção entre regulamentação e padronização. As regras de padronização, implantadas de maneira obrigatória ou voluntária, voltam-se mais ao processo do que ao objetivo, uma vez que di- 
tam a maneira como as companhias devem se comportar. Da mesma forma, regulamentar pode ou não padronizar a divulgação de informações ambientais e isso dependerá da forma de adoção do regulamento. Se o regulamento voltar-se ao objetivo final, ele não servirá como instrumento de padronização. Por outro lado, se for voltado ao processo, será considerado como uma forma de padronização obrigatória.

Outro ponto distintivo entre os dois conceitos é o nível de especificidade apresentado pelos requerimentos. A padronização é mais específica e serve para detalhar a forma como deve ser conduzido o processo. Já a simples regulamentação direciona-se mais ao objeto

\section{DESENHO METODOLÓGICO}

Para atender o objetivo proposto por esta pesquisa, optou-se por uma abordagem predominantemente quantitativa, de cunho descritivo, utilizando-se das ferramentas da análise de conteúdo e da estatística para analisar e apresentar os dados encontrados. $\mathrm{O}$ trabalho estudou, basicamente, a relação entre duas variáveis, a regulamentação das informações ambientais e o nível de disclosure ambiental das empresas da amostra.

\subsection{Universo e amostra}

Segundo Lopes (2002, pg. 48), um dos maiores desafios em se analisarem as consequências de diferentes marcos regulatórios é isolar a variável em questão. Como foi visto na parte sobre os determinantes da evidenciação ambiental, as variáveis tamanho da companhia, setor econômico de atuação e características culturais dos países influenciam, contundentemente, as práticas de evidenciação ambiental. Para realizar essa pesquisa, optou-se por uma amostra intencional e não probabilística que tenta isolar essas influências, sendo assim, os resultados obtidos serão frutos das distinções entre os países atribuídas aos seus diferentes estilos regulatórios de final e se preocupa mais em punir os infratores. Para os regulamentos não padronizadores, o importante é cumprir o que suas regras ditam, independentemente do modo como isso será feito. Na evidenciação ambiental, existem exemplos dos dois tipos de instrumentos: os regulatórios, que se preocupam, apenas, com os resultados finais (como é o caso de várias regras de evidenciação ambiental nos relatórios anuais, elas apenas dizem o que deve ser evidenciado, mas não de que forma) e existem os padrões de relatórios ambientais, que podem ser obrigatórios ou voluntários e detalham com especificidade a forma como as companhias devem divulgar suas informações ambientais.

evidenciação ambiental.

A primeira variável isolada foram as características culturais e jurídicas dos países analisados. Foram selecionados quatro países (Estados Unidos, Inglaterra, Austrália e Canadá) considerados desenvolvidos, que apresentam características culturais anglosaxônicas e que possuem sistema jurídico baseado no Common Law (NOBES; PARKER, 2008). A segunda variável isolada foi o setor econômico de atuação das companhias. Com o intuito de isolar esse quesito, optou-se pela coleta de empresas de apenas um setor industrial, o de Petróleo e Gás Natural. O setor de Petróleo e Gás Natural foi escolhido devido a duas razões principais: é uma atividade de grande impacto no meio ambiente e uma das mais regulamentadas em termos ambientais. A terceira variável isolada foi o tamanho da empresa. De acordo com Hart e Oulton (1996), o número de empregados, o valor dos ativos, o faturamento, o valor adicionado e o valor de mercado são as principais medidas de tamanho de uma companhia. Os autores ressaltam que cada uma delas apresenta diversas limitações e a escolha da medida mais adequada deve ser feita de acordo com a dis- 
ponibilidade dos dados. Para essa pesquisa, devido, principalmente, à acessibilidade dos dados, a medida de tamanho adotada foi o faturamento bruto do exercício de 2007.

Após selecionar as variáveis que seriam isoladas, partiu-se para a escolha das companhias analisadas. Para traçar a população base do trabalho, foram selecionadas as Bolsas de Valores com maior representatividade em termos de volume de negócios em cada país pesquisado: no caso dos Estados Unidos foi a Bolsa de Nova Iorque (New York Stock Exchange - NYSE); no Canadá foi a Bolsa de Toronto (Toronto Stock Exchange - TSX); na Inglaterra foi a Bolsa de Londres (London Stock Exchange - LSX) e na Austrália foi a Bolsa da Austrália (Australian Stock Exchange - ASX). Após a seleção das Bolsas de Valores, foram separadas todas as companhias pertencentes ao setor designado pelas próprias entidades como Petróleo e Gás Natural. Ao todo foram pesquisadas $385 \mathrm{com}$ panhias, dessas, 263 (68\%) apresentaram website ativo e informações sobre o faturamento no exercício 2007. Algumas companhias selecionadas foram concebidas sob a forma de parceria de negócios (Trust) e muitas dessas parcerias estavam em fase de exploração e não haviam começado suas atividades, por isso foram excluídas da amostra.

Para coletar as informações sobre a receita foram analisadas as demonstrações de resultado do exercício, ano base 2007, de todas as companhias restantes. Tendo em vista que as companhias escolhidas são de diferentes países e, por isso, muitas vezes publicam seus resultados em moeda local, foi necessário uniformizar os dados, ou seja, converter o faturamento de todas as companhias para uma única moeda. A moeda escolhida foi o dólar norte-americano e para fazer a conversão foi utilizada a data do fechamento do exercício e a respectiva cotação referente à moeda local disponível no website do Banco Central do Brasil (2009). Após transformar o faturamento em US\$ dólar, foi a vez de es- colher as companhias que apresentaram a maior similaridade nesse quesito. A maior dificuldade enfrentada nessa parte foi a escolha compatível das empresas com base na sua receita. As maiores companhias de petróleo norte-americanas apresentaram uma receita muito superior em comparação com as maiores companhias de petróleo dos demais países. Para contornar esse problema, optou-se pela escolha de um teto máximo para o faturamento de 1,3 bilhão de dólares, o que representa o maior faturamento entre as 30 menores companhias norte-americanas. Para os demais países foram selecionadas as 30 maiores companhias com faturamento abaixo deste limite. A escolha de $30 \mathrm{com}$ panhias por país foi motivada, principalmente, pela necessidade de homogeneidade dos valores das receitas brutas. Nos EUA existem 70 companhias de petróleo listadas na NYSE, dessas, 30 apresentaram faturamento abaixo de US\$1,3 bilhão, porém, as próximas faixas acima desse valor são muito superiores, o que tornaria inviável a comparação com os outros países. Ao todo foram selecionadas 120 companhias abertas e isso representa $46 \%$ de todas as companhias de petróleo listadas nesses países com website e faturamento passíveis de verificação.

\subsection{Coleta e classificação dos dados}

Depois de escolher a amostra de empresas foi necessário selecionar a fonte de informações ambientais que seria analisada nesta pesquisa. Segundo Gray e Bebbington (2001), existem, basicamente, três formas de as empresas divulgarem informações ambientais: por meio de seus relatórios anuais, mediante seus relatórios ambientais específicos e por intermédio da internet. Esta pesquisa focou a coleta na primeira opção, ou seja, nos relatórios anuais: RA do exercício de 2007. O ano de 2007 foi escolhido por ser o mais atual e com a maior probabilidade de as empresas possuírem o relatório anual, uma vez que os dados foram coletados no começo de 2009 e muitas ainda 
não apresentavam RA do ano base 2008 .

A escolha do relatório anual foi motivada, principalmente, pela disponibilidade dessa fonte de informação. Além disso, o relatório anual é o canal preferido pelas empresas para divulgar suas informações corporativas (DEEGAN; RANKIN, 1996; EPSTEIN; FREEDMAN, 1994). Embora os relatórios socioambientais ou de sustentabilidade também sejam importantes veículos disseminadores das informações ambientais (GRAY; BEBBINGTON, 2001; RIBEIRO; VAN BELLEN, 2008), eles são publicados, em sua maioria, no meio de grandes corporações, as quais não foram inclusas nessa pesquisa. Essa tendência foi confirmada pela amostra, pois, das $120 \mathrm{em}$ presas analisadas, apenas cinco (menos do que 5\%) apresentaram relatórios ambientais específicos. Dessa forma, devido, principalmente, a sua baixa representatividade para os resultados, optou-se por não incluí-los na pesquisa.

Outro fator a ser definido foi o local em que essas informações seriam coletadas nos relatórios anuais. As regras legais encontradas nos países pesquisados exigem que os relatórios anuais apresentem duas partes: as demonstrações financeiras e a análise da diretoria (conhecida como Managements Discussion and Analysis - MD\&A). O problema de se aglutinar as informações dessas duas partes é que elas apresentam características distintas. Enquanto as informações contábeis são auditadas, as do MD\&A não são e isso pode acarretar uma grande discrepância na hora de se compararem os dados. Para evitar esse transtorno, as informações contábeis obrigatórias foram analisadas à parte, em uma classificação especialmente criada para elas.

Após a coleta e leitura dos relatórios, o próximo passo foi mensurar o nível de evidenciação ambiental de cada companhia. Para medir o nível de disclosure ambiental foi utilizada uma escala adaptada de dois trabalhos que são referência nessa área: o de Wiseman (1982) e o de Clarkson et al. (2008). Ambos os trabalhos possuem em comum o objetivo de estudar a performance ambiental por meio do material "verde" que é divulgado pelas companhias. A grande diferença reside no fato de que o estudo de Clarkson et al. (2008) utilizou, apenas, informações coletadas na internet e em relatórios não discricionários e o de Wiseman (1982) utilizou, apenas, os relatórios anuais para coleta. A junção dos dois trabalhos foi necessária devido aos seus focos diferenciados. A classificação proposta por Clarkson et al. (2008) é mais completa e abrangente, além de tomar como base na sua construção o GRI. Já a escala de Wiseman (1982) é mais utilizada para analisar os relatórios anuais, pois inclui informações sobre litígios e passivos ambientais, itens não abordados no estudo de Clarkson et al. (2008), por esses tratarem apenas com informações não discricionárias. Tendo em vista que essa pesquisa trabalharia com as duas qualidades de informações (discricionárias e não discricionárias), foi necessária a utilização de uma escala que juntasse os dois trabalhos.

A escala adaptada das duas pesquisas citadas anteriormente contém 110 itens divididos em três grupos e nove subgrupos de informações. Os grupos foram utilizados para classificar o tipo geral de informação evidenciada, que pode ser quantitativa, descritiva ou das demonstrações contábeis. As informações quantitativas são aquelas direcionadas diretamente à performance ambiental da companhia. Esse tipo de informação é mais útil para o processo decisório, pois permite avaliar de maneira objetiva os indicadores e as ações ambientais de determinada organização. As categorias criadas para classificar essas informações foram: (I) Indicadores de desempenho ambiental; (II) Gastos ou investimentos ambientais; (III) Litígios e processos ambientais e (IV) Estrutura de governança e adaptação do sistema administrativo. As informações descritivas, por sua vez, são aquelas ligadas às intenções e às políticas das companhias em termos ambientais e esse tipo de informação é mais útil para avaliar os riscos e o perfil ambiental de 
determinada empresa. As categorias inseridas nesse grupo são: (V) Credibilidade das políticas ambientais; (VI) Visão e estratégia; (VII) Perfil ambiental e (VIII) Iniciativas ambientais genéricas. Por fim, as informações contábeis foram classificadas em uma escala específica representada pelo item IX (informações ambientais no sistema contábil da empresa), que abrange todas as demonstrações contábeis e as notas explicativas.

Outro ponto que cabe destacar é que a moldura para medir o nível de evidenciação dos dados ambientais que foi utilizada nesta pesquisa pode ser adaptada a qualquer informação não prevista anteriormente, ou seja, qualquer nova informação evidenciada foi acrescentada ao estudo sob a forma de um novo número, sendo assim, nenhuma companhia teve seu nível de evidenciação ambiental prejudicado por sua informação não fazer parte da escala, além disso, para classificar os dados na Tabela foi utilizado um formato de checklist. Com isso, as informações são classificadas pela sua existência ou não existência, independentemente da quantidade de vezes que ela aparece.

Entre as limitações da pesquisa está a questão da pertinência que envolve dados evidenciados pelas companhias. Quando se trabalha com escalas pontuadas, algumas informações da moldura podem não ser pertinentes às empresas envolvidas na pesquisa o que penalizaria a sua performance em relação às demais. Por exemplo, as companhias que não têm processos ou litígios ambientais poderiam fi- car com um nível de evidenciação menor em comparação àquelas que possuem; por outro lado, a não divulgação da informação é um aspecto mais negativo do que evidenciar uma informação ruim (DYE, 1985). Para contornar esse problema, nesta pesquisa foi considerado se a empresa divulgou ou não divulgou a informação, independentemente da sua ocorrência. As empresas que divulgam que não possuem informações negativas serão consideradas como aquelas que divulgam possuir litígios ambientais. Assim, as únicas penalizadas serão as que não divulgam nada sobre determinado aspecto, uma vez que todas as informações da escala são pertinentes a essa atividade.

Para testar as hipóteses foi escolhido o teste não paramétrico Kruskal-Wallis (teste $\mathrm{H})$. A escolha desse teste foi motivada, principalmente, por ele fugir dos requisitos de distribuição normal e servir para comparar as diferenças de várias amostras independentes. De acordo com Black (2005), o teste H é uma alternativa ao teste paramétrico quando as suas assunções de normalidade e homogeneidade de variância não podem ser satisfeitas. Quanto às vantagens de utilizar testes não paramétricos, Siegel e Castellan (2006) argumentam que os testes não paramétricos são mais flexíveis, ou seja, adaptam-se a uma variedade de dados maior, além disso, são mais aconselháveis quando se trata de dados que estejam inerentemente classificados em postos, como é o caso deste trabalho. Como ferramenta estatística para realizar o teste foi utilizado o sistema SPSS ${ }^{\circledast}$ versão 17.

\section{APRESENTAÇÃO E ANÁLISE DOS RESULTADOS}

A apresentação dos resultados foi dividida em duas partes. Em primeiro lugar foi feita uma síntese e uma análise das normas que regulam a EAC dos países selecionados para a pesquisa, logo após, foram apresentados os resultados do teste estatístico dos relatórios da diretoria e das demonstrações contábeis com os respectivos comentários.

\subsection{Comparação dos marcos regulatórios dos países integrantes da pesquisa}

Buhr (2007) e Fleischman e Schuele (2006) afirmam que os regulamentos ou padrões de evidenciação ambiental que afetam os relatórios anuais podem ser implantados 
sob três perspectivas: a legal, a de mercado e a contábil. Essa classificação aborda todas as formas conhecidas de regulação obrigatória das informações ambientais divulgadas pelas empresas. As normas ou regulamentos que foram pesquisados podem influenciar de maneira direta ou indireta tanto o nível quanto a variedade das informações ambientais divulgadas nos relatórios corporativos. As normas pesquisadas, na perspectiva legal, foram os códigos ou leis ambientais e as leis corporativas. Quanto às normas de mercado ou contábeis, foram relacionados todos os que contêm algum tipo de relação com a evidenciação de informações ambientais. Um resumo de toda a legislação envolvendo a EAC dos países pesquisados pode ser visualizado no Quadro 1.

Como pode ser observado no respectivo quadro, as maiores diferenças entre os países estão no órgão emissor do regulamento, na especificidade dos regulamentos, nos mecanismos de coerção e na quantidade de regulamentação. O país que apresentou o marco regulatório de evidenciação ambiental mais extenso e com maior poder de enforcement foi os Estados Unidos. Ao analisar com profundidade os requerimentos norte-americanos, notase que eles são bastante específicos quanto ao conteúdo e à forma como devem ser apresentadas as informações ambientais. Além disso, os EUA é o único a possuir u $\mathrm{m}$ processo regulatório totalmente centralizado (a Securities and Exchange Comission - SEC - cria, implanta, fiscaliza e pune os infratores das suas normas) e um padrão contábil que trata especificamente da contabilização de eventos ambientais.

Quadro 1 Síntese dos regulamentos diretos de cada país

\begin{tabular}{|c|c|c|c|c|c|c|c|c|}
\hline$\frac{n}{\tilde{N}}$ & $\begin{array}{l}\text { Forma de } \\
\text { Emissão e } \\
\text { fiscaliza- } \\
\text { ção do } \\
\text { regula- } \\
\text { mento }\end{array}$ & $\begin{array}{l}\text { Local de } \\
\text { homolo- } \\
\text { gação }\end{array}$ & $\begin{array}{l}\text { Número da } \\
\text { norma e data } \\
\text { em que foi } \\
\text { aprovada }\end{array}$ & $\begin{array}{l}\text { Grau de } \\
\text { coerção }\end{array}$ & $\begin{array}{l}\text { Parte do } \\
\text { relatório } \\
\text { envolvida }\end{array}$ & Sínteses dos requerimentos & $\begin{array}{l}\text { Nível de } \\
\text { especifici- } \\
\text { dade }\end{array}$ & $\begin{array}{l}\text { Itens im- } \\
\text { pactados } \\
\text { pela } \\
\text { norma }\end{array}$ \\
\hline \multirow{5}{*}{ 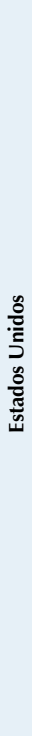 } & \multirow{4}{*}{ 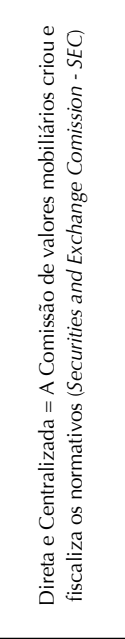 } & \multirow{4}{*}{ 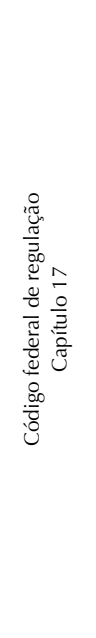 } & $\begin{array}{l}\text { Regulation } \\
\text { S-X, } \\
\$ 210.4-10, \\
\text { (c), (6), (i) } \\
1978\end{array}$ & \multirow{5}{*}{ 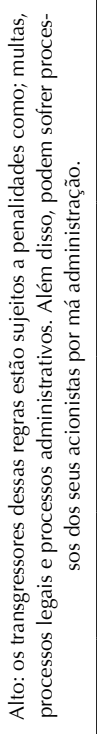 } & $\begin{array}{l}\text { Dem. } \\
\text { Contábeis } \\
\text { e relató- } \\
\text { rio da } \\
\text { diretoria }\end{array}$ & $\begin{array}{l}\text { Requer que as empresas norte-americanas } \\
\text { reconheçam e capitalizem os custos futuros } \\
\text { com o abandono e o desmantelamento de } \\
\text { qualquer ativo de posse da companhia. } \\
\text { Entre esses custos estão inseridos os custos } \\
\text { de restauração ambiental do local atingido } \\
\text { pela atividade do bem. }\end{array}$ & Alto & $\begin{array}{l}\text { Itens III } \\
(30), \text { II } \\
(24), \mathrm{VII} \\
\text { (72) e IX } \\
\text { (NI) }\end{array}$ \\
\hline & & & $\begin{array}{l}\text { Regula- } \\
\text { tion S-K, } \\
\$ 229.101 \\
\text { (c), (xii) } 1988\end{array}$ & & $\begin{array}{l}\text { Relatório } \\
\text { da } \\
\text { diretoria }\end{array}$ & $\begin{array}{l}\text { Requer que as companhias divulguem o } \\
\text { efeito presente e futuro que as leis ou reque- } \\
\text { rimentos ambientais geram aos seus gastos } \\
\text { de capital, ganhos e competitividade. }\end{array}$ & Médio & $\begin{array}{l}\text { Itens II } \\
(23) \text { e VII } \\
(62,65 \\
70,71 \mathrm{e} \\
75)\end{array}$ \\
\hline & & & $\begin{array}{l}\text { Regula- } \\
\text { tion S-K, } \\
\$ 229.103,(5) \\
1988\end{array}$ & & $\begin{array}{l}\text { Relatório } \\
\text { da } \\
\text { diretoria }\end{array}$ & $\begin{array}{l}\text { Requer que companhias divulguem qual- } \\
\text { quer possibilidade ou existência de processo } \\
\text { legal ou administrativo de efeito material } \\
\text { que envolva penalidades decorrentes de } \\
\text { problemas ou transgreções ambientais. }\end{array}$ & Alto & $\begin{array}{l}\text { Itens III } \\
(27,28 \\
\text { e } 29) \text { II } \\
(19)\end{array}$ \\
\hline & & & $\begin{array}{l}\text { Regulation } \\
\text { S-K, } \\
\S 229.303, \text { (a) } \\
1988\end{array}$ & & $\begin{array}{l}\text { Relatório } \\
\text { da dire- } \\
\text { toria }\end{array}$ & $\begin{array}{l}\text { Requer que as companhias divulguem } \\
\text { informações sobre os seus riscos ambientais } \\
\text { (incluindo os legais) e como elas fazem para } \\
\text { minimizá-los. }\end{array}$ & Médio & $\begin{array}{l}\text { Item VII } \\
(63,67 \\
69,73 \\
74)\end{array}$ \\
\hline & 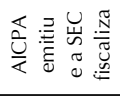 & $\cong \frac{2}{s}$ & $\begin{array}{c}\text { SOP 96-1 } \\
1996\end{array}$ & & $\begin{array}{l}\text { Dem. } \\
\text { Contá- } \\
\text { beis }\end{array}$ & $\begin{array}{l}\text { Aponta como as companhias devem reco- } \\
\text { nhecer contabilmente suas obrigações com } \\
\text { remediação ambiental. }\end{array}$ & Alto & $\begin{array}{l}\text { Item IX } \\
\text { (Geral) }\end{array}$ \\
\hline 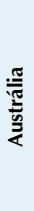 & 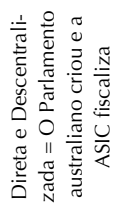 & 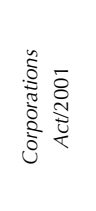 & $\begin{array}{l}\text { Artigo } 299 \\
\text { Item } 1(\mathrm{f}) \\
2001\end{array}$ & 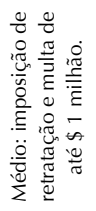 & $\begin{array}{l}\text { Relatório } \\
\text { da } \\
\text { diretoria }\end{array}$ & $\begin{array}{l}\text { Requer que as companhias evidenciem se } \\
\text { estão sujeitas à alguma lei ou a regulamento } \\
\text { ambiental e qual a sua performance em } \\
\text { relação a tais regulamentos }\end{array}$ & Alto & $\begin{array}{l}\text { Item VII } \\
\text { (62 e 64) }\end{array}$ \\
\hline
\end{tabular}


continuação

\begin{tabular}{|c|c|c|c|c|c|c|c|c|}
\hline$\frac{n}{\tilde{N}}$ & $\begin{array}{c}\text { Forma de } \\
\text { Emissão e } \\
\text { fiscaliza- } \\
\text { ção do } \\
\text { regula- } \\
\text { mento }\end{array}$ & $\begin{array}{c}\text { Local de } \\
\text { homolo- } \\
\text { gação }\end{array}$ & $\begin{array}{l}\text { Número da } \\
\text { norma e data } \\
\text { em que foi } \\
\text { aprovada }\end{array}$ & $\begin{array}{l}\text { Grau de } \\
\text { coerção }\end{array}$ & $\begin{array}{c}\text { Parte do } \\
\text { relatório } \\
\text { envolvida }\end{array}$ & Sínteses dos requerimentos & $\begin{array}{l}\text { Nível de } \\
\text { especifici- } \\
\text { dade }\end{array}$ & $\begin{array}{l}\text { Itens im- } \\
\text { pactados } \\
\text { pela } \\
\text { norma }\end{array}$ \\
\hline \multirow{3}{*}{ 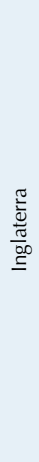 } & \multirow{3}{*}{ 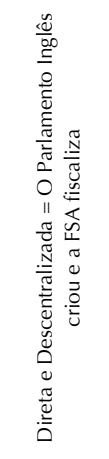 } & \multirow{3}{*}{ 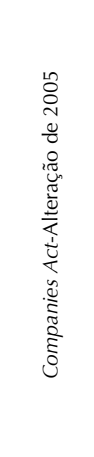 } & $\begin{array}{l}\text { Artigo } 172 \\
\text { Item } 1(d) \\
2005\end{array}$ & 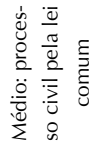 & $\begin{array}{l}\text { Relatório } \\
\text { da } \\
\text { diretoria }\end{array}$ & $\begin{array}{l}\text { Requer que os diretores das companhias } \\
\text { destaquem que o respeito ao meio ambiente } \\
\text { é um componente da busca pelo sucesso de } \\
\text { sua empresa }\end{array}$ & Baixo & $\begin{array}{l}\text { Item VI } \\
\text { (Não es- } \\
\text { pecífico) }\end{array}$ \\
\hline & & & $\begin{array}{l}\text { Artigo } 417 \\
\text { Item 5(b) (i) } \\
2005\end{array}$ & \multirow{2}{*}{ 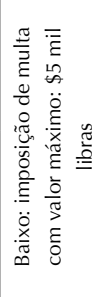 } & $\begin{array}{l}\text { Relatório } \\
\text { da } \\
\text { diretoria }\end{array}$ & $\begin{array}{l}\text { Requer que as companhias divulguem na } \\
\text { parte de sua revisão de negócios a sua perfor- } \\
\text { mance em relação aos assuntos de natureza } \\
\text { ambiental. }\end{array}$ & Baixo & $\begin{array}{l}\text { Itens IV e } \\
\text { VI (Não } \\
\text { especí- } \\
\text { fico) }\end{array}$ \\
\hline & & & $\begin{array}{l}\text { Artigo } 417 \\
\text { Item } 6(\mathrm{~b}) \\
2005\end{array}$ & & $\begin{array}{l}\text { Relatório } \\
\text { da } \\
\text { diretoria }\end{array}$ & $\begin{array}{l}\text { Requer que as companhias divulguem uma } \\
\text { revisão de seu negócio de maneira aprofun- } \\
\text { dada e ilustrativa e faculta a utilização de } \\
\text { indicadores de performance, entre eles os } \\
\text { ambientais, para fazer isso. }\end{array}$ & Baixo & $\begin{array}{l}\text { Itens IV e } \\
\text { VI (Não } \\
\text { especí- } \\
\text { fico) }\end{array}$ \\
\hline \multirow{4}{*}{ 永 } & \multirow{4}{*}{ 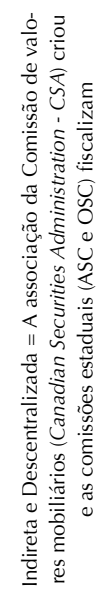 } & \multirow{4}{*}{ 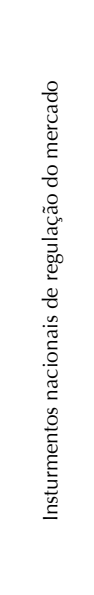 } & $\begin{array}{l}\text { NI } 51-102 ; \\
2 ; 1 ; 1.4 ; \text { (d) } \\
\text { (i)(ii) } 2004\end{array}$ & \multirow{4}{*}{ 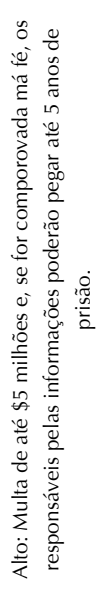 } & $\begin{array}{l}\text { Relatório } \\
\text { da } \\
\text { diretoria }\end{array}$ & $\begin{array}{l}\text { Requer que as companhia divulguem na } \\
\text { parte de resultados operacionais qualquer } \\
\text { influência que assuntos ambientais têm } \\
\text { sobre seus projetos presentes ou futuros. }\end{array}$ & Baixo & $\begin{array}{l}\text { Item VII } \\
\text { (Não es- } \\
\text { pecífico) }\end{array}$ \\
\hline & & & $\begin{array}{l}\text { NI } 51-102 ; \\
2 ; 5 ; 5.1 ;(1) \\
\quad \text { (k) } 2004\end{array}$ & & $\begin{array}{l}\text { Relatório } \\
\text { da } \\
\text { diretoria }\end{array}$ & $\begin{array}{l}\text { Requer que as companhias divulguem os } \\
\text { efeitos financeiros e operacioanais que as } \\
\text { leis e regulamentos de proteção ambiental } \\
\text { podem gerar sobre seus gastos de capital, } \\
\text { seus ganhos e sua competitividade. }\end{array}$ & Alto & $\begin{array}{l}\text { Item VII } \\
(62,65 \\
70,71 \text { e } \\
75)\end{array}$ \\
\hline & & & $\begin{array}{l}\text { NI } 51-102 ; \\
2 ; 5 ; 5.1 ;(4) \\
\quad 2004\end{array}$ & & $\begin{array}{l}\text { Relatório } \\
\text { da } \\
\text { diretoria }\end{array}$ & $\begin{array}{l}\text { Requer das companhias que implantaram } \\
\text { qualquer política ambiental que seja funda- } \\
\text { mental para suas operações a divulgação de } \\
\text { quais são essas políticas e dos passos dados } \\
\text { pela companhia para sua implementação. }\end{array}$ & Baixo & $\begin{array}{l}\text { Item VI } \\
\text { (Não es- } \\
\text { pecífico) }\end{array}$ \\
\hline & & & $\begin{array}{l}\text { NI } 51-102 ; \\
2 ; 5 ; 5.2 \\
2004\end{array}$ & & $\begin{array}{l}\text { Relatório } \\
\text { da } \\
\text { diretoria }\end{array}$ & $\begin{array}{l}\text { Requer das companhias uma descrição de } \\
\text { todos os fatores de risco que podem afetar } \\
\text { as suas atividades, incluíndo os riscos } \\
\text { ambientais. }\end{array}$ & Médio & $\begin{array}{c}\text { Item VII } \\
\text { (63 e 67) }\end{array}$ \\
\hline
\end{tabular}

Quanto aos outros países, o modelo regulatório canadense foi o que mais se aproximou do norte-americano em termos de conteúdo e exigibilidade das suas normas. Essa similaridade já havia sido percebida por diversos trabalhos anteriores como os de Buhr e Freedman (1996), Buhr e Freedman (2001) e Gray et al. (1996). Mas, apesar da aproximação dos marcos regulatórios dos dois países, eles apresentam algumas diferenças como níveis de coerção diferentes e formas de emissão e fiscalização dos regulamentos. Além disso, os EUA apresentam uma maior extensão regulatória no que tange à EAC do que os canadenses.
O terceiro país que apresentou o modelo regulatório de disclosure ambiental mais desenvolvido foi a Inglaterra. O modelo inglês diferencia-se do norte-americano e do canadense em três principais aspectos: (1) ele foi imposto pela legislação corporativa e não pelo órgão regulador do mercado, ou seja, o processo de criação e fiscalização é totalmente descentralizado; (2) ele não apresenta mecanismo de enforcement tão severo como os dois países anteriores e (3) o conteúdo ambiental que deve ser divulgado é diferente do apresentado pelo Canadá e EUA. Essas diferenças encontradas no modelo regulatório Inglês são compatíveis com as diferenças detectadas anteriormen- 
te pelo estudo de Holland e Foo (2003). Os pesquisadores afirmam que a moldura regulatória norte-americana é muito mais rígida e fechada do que a britânica.

Outra explicação para essas diferenças entre os EUA e a Inglaterra está na influência cultural sobre o desenvolvimento dos seus modelos regulatórios. Enquanto o modelo inglês é visivelmente orientado pela corrente européia, mais preocupada com o desempenho ambiental do que com o impacto financeiro, o modelo norte-americano é mais voltado para as consequências dos atos ambientais sobre a posição competitiva e financeira da companhia (UNERMAN; BEBBINGTON; O'DWYER, 2007). Um ponto que exemplifica isso claramente é a previsão nos regulamentos britânicos (mesmo que timidamente e de maneira facultativa) das suas companhias evidenciarem índices ou indicadores de performance ambiental como complemento às informações divulgadas nos relatórios financeiros.

Um aspecto que deve ser salientado no caso britânico é a data de implantação das suas normas ambientais. Enquanto os demais países apresentam requerimentos com, no mínimo, 6 anos de implantação, os regulamentos de evidenciação ambiental ingleses foram introduzidos na alteração de 2005 da lei das companhias na Inglaterra e, por isso, suas empresas podem ainda estar em fase de adaptação a esse novo regime, o que impactará diretamente no seu nível, de conformidade com os novos requerimentos.

O último país analisado foi a Austrália. A criação do modelo regulatório australiano é bastante similar ao britânico, pois ambos foram feitos por seus parlamentos. A grande diferença entre os dois modelos está na rigidez de seus instrumentos de coerção (no caso australiano um pouco mais ríspido) e na extensão de seus requerimentos de divulgação. A Austrália, ao contrário dos outros países, apresenta a norma com menor requerimento informacional; para satisfazer à legislação australiana, as companhias abertas necessitam divulgar, somente, se estão sujeitas ou não às normas ambientais e de que forma é a sua performance em relação a eles (se existe conformidade ou não). O modelo Australiano segue mais a corrente norte-americana do que a européia, pois se preocupa, fundamentalmente, com o impacto das leis ambientais na situação financeira ou posição competitiva da entidade.

Em relação ao tratamento das informações contábeis, os EUA foi o único país que apresentou alguma regra específica para contabilizar eventos ambientais. Os demais países apresentaram requerimentos ambientais dentro de padrões variados, como contabilização de provisões e contingências ou reavaliação de ativos. Em decorrência disso, é esperado que os EUA apresentem uma evidenciação ambiental mais extensa também nas demonstrações contábeis.

\subsection{Resultados do teste estatístico}

Todas as 120 empresas da amostra publicaram relatórios anuais completos no ano base de 2007. Desses relatórios, foram lidas 10.126 páginas e coletadas 1.276 informações ambientais que foram separadas em dois grupos e nove subgrupos de informações relativas ao meio ambiente. Como foi observado na introdução deste trabalho, o seu objetivo principal era o de verificar se as companhias analisadas reagem aos estímulos regulatórios específicos de disclosure ambiental, por meio da comparação de diferenças entre a evidenciação ambiental das companhias de um setor, o de petróleo, com as variações existentes nos instrumentos regulatórios dos países analisados. Os resultados do teste estatístico estão segregados por tipo de informação ambiental divulgada e podem ser observados nas Tabelas a seguir. 
Tabela 1 Resultados descritivos das informações encontradas

\begin{tabular}{|c|c|c|c|c|c|c|c|c|}
\hline \multirow[b]{2}{*}{$\begin{array}{l}\text { Categoria de } \\
\text { Informações }\end{array}$} & \multirow[b]{2}{*}{$\underset{\text { (amostra) }}{\mathrm{N}}$} & \multirow[b]{2}{*}{ Média } & \multirow[b]{2}{*}{$\begin{array}{l}\text { Desvio } \\
\text { Padrão }\end{array}$} & \multirow[b]{2}{*}{ Mínimo } & \multirow[b]{2}{*}{ Máximo } & \multicolumn{3}{|c|}{ Percentil } \\
\hline & & & & & & $25^{\circ}$ & $\begin{array}{c}50^{\circ} \\
\text { (Mediana) }\end{array}$ & $75^{\circ}$ \\
\hline Item I & 120 & 0,0583 & 0,235360 & 0,0000 & 1,0000 & 0,0000 & 0,0000 & 0,0000 \\
\hline Item II & 120 & 01917 & 0,523340 & 0,0000 & 3,0000 & 0,0000 & 0,0000 & 0,0000 \\
\hline Item III & 120 & 0,6833 & 1,012390 & 0,0000 & 4,0000 & 0,0000 & 0,0000 & 1,0000 \\
\hline Item IV & 120 & 0,8583 & 1,323960 & 0,0000 & 6,0000 & 0,0000 & 0,0000 & 1,0000 \\
\hline Item V & 120 & 0,7667 & 1,207350 & 0,0000 & 6,0000 & 0,0000 & 0,0000 & 1,0000 \\
\hline Total Itens Quantitativos & 120 & 2,5583 & 2,513140 & 0,0000 & 13,0000 & 1,0000 & 2,0000 & 4,0000 \\
\hline Item VI & 120 & 1,2000 & 1,585650 & 0,0000 & 7,0000 & 0,0000 & 1,0000 & 2,0000 \\
\hline Item VII & 120 & 5,3417 & 4,024080 & 0,0000 & 15,0000 & 2,0000 & 3,0000 & 8,7500 \\
\hline Item VIII & 120 & 1,5333 & 2,386700 & 0,0000 & 14,0000 & 0,0000 & 0,5000 & 2,0000 \\
\hline Item IX & 120 & 0,9750 & 1,386990 & 0,0000 & 8,0000 & 0,0000 & 0,5000 & 1,0000 \\
\hline Total Itens Qualitativos & 120 & 8,0750 & 5,334460 & 1,0000 & 32,0000 & 4,0000 & 7,0000 & 11,0000 \\
\hline Total Geral & 120 & 10,6333 & 7,174810 & 1,0000 & 41,0000 & 5,0000 & 9,0000 & 15,0000 \\
\hline
\end{tabular}

Conforme o observado na Tabela 1, os itens descritivos apresentaram uma divulgação muito superior em relação aos itens quantitativos. Alguns itens quantitativos apresentaram um nível de divulgação muito baixo, como é o caso dos itens I, II, III, IV e V, em que $75 \%$ da amostra apresentaram nenhuma divulgação ou apenas um tipo de informação divulgada. O grande destaque foi o item VII, que concentra a maioria das informações obrigatórias nos regulamentos corporativos dos países analisados. O pior desempenho foi do item I, que traz os índices de desempenho ambiental, informação que é totalmente voluntária, ou seja, não está inclusa em nenhum regulamento obrigatório nos países analisados. As demonstrações contábeis (item IX) apresentaram um índice próximo dos itens qualitativos, o que mostra que elas são razoavelmente utilizadas para divulgar informações ambientais.

A próxima análise é a dos rankings das quantidades de informações evidenciadas de acordo com cada item. De maneira geral, os resultados apresentaram-se coerentes com a extensão dos regulamentos apresentados. As companhias norte-americanas da amostra, as mais reguladas em termos de extensão regulatória sobre evidenciação ambiental, foram as que mais divulgaram informações ambientais. As demais companhias, também, apresentaram uma quantidade de divulgação ambiental equivalente à extensão dos regulamentos dos seus países. Na Tabela 2, está essa classificação, assim como a média geral e individual do ranking de evidenciação ambiental.

Tabela 2 Ranking dos itens mais divulgados por país

\begin{tabular}{l|c|c|c|c|c|c|c}
\hline \multirow{2}{*}{$\begin{array}{c}\text { País } \\
\text { analisado }\end{array}$} & $\begin{array}{c}\text { N } \\
\text { (amostra) }\end{array}$ & \multicolumn{7}{c}{ Categorias de Informações Analisadas } \\
\cline { 3 - 9 } & & Item I & Item II & Item III & Item IV & Item V & Tot. Quanti \\
\hline Inglaterra & 30 & 61,00 & 55,83 & 44,37 & 73,45 & 66,93 & 62,68 \\
\hline Austrália & 30 & 61,00 & 52,00 & 42,82 & 65,87 & 59,18 & 49,20 \\
\hline EUA & 30 & 61,00 & 74,23 & 98,27 & 44,77 & 67,80 & 81,67 \\
\hline Canadá & 30 & 59,00 & 59,93 & 56,55 & 57,92 & 48,08 & 48,45 \\
\hline Total & 120 & 60,50 & 60,50 & 60,50 & 60,50 & 60,50 & 60,50 \\
\hline
\end{tabular}




\begin{tabular}{l|c|c|c|c|c|c|c}
\multicolumn{1}{c}{$\begin{array}{c}\text { País } \\
\text { analisado }\end{array}$} & $\begin{array}{c}\text { N } \\
\text { (amostra) }\end{array}$ & \multicolumn{7}{c}{ Categorias de Informações Analisadas } \\
\cline { 3 - 9 } & Item VI & Item VII & Item VIII & Tot. Quali & \multicolumn{1}{c}{ Item IX } & Tot. Geral \\
\hline Inglaterra & 30 & 72,17 & 35,52 & 67,60 & 47,18 & 45,70 & 53,12 \\
\hline Austrália & 30 & 61,77 & 36,33 & 58,25 & 37,15 & 60,47 & 38,73 \\
\hline EUA & 30 & 41,18 & 102,27 & 52,98 & 91,37 & 94,70 & 89,05 \\
\hline Canadá & 30 & 66,88 & 67,88 & 63,13 & 66,30 & 41,13 & 61,10 \\
\hline Total & 120 & 60,50 & 60,50 & 60,49 & 60,50 & 60,50 & 60,50 \\
\hline
\end{tabular}

De maneira individual, as diferenças regulatórias foram mais perceptíveis. Ao analisar a Tabela 2, percebe-se que as maiores diferenças entre as companhias da amostra estão concentradas nos itens mais regulamentados nos EUA e em algumas informações na Inglaterra. Entre os demais países não afetados pelas regras regulatórias a diferença é pequena. Um exemplo disso são os itens II e III, nos quais os EUA são regulamentados e os demais países não são. As diferenças nesses itens entre os demais países não regulamentados são menores em comparação com os EUA. O item VII, também, reflete as diferenças em termos de extensão regulatória de cada país. Nesse item, os países com os regulamentos mais extensos ficaram em primeiro e segundo lugar. Para as demonstrações contábeis, o nível de disclosure das companhias de petróleo norte-americanas novamente foi bem maior do que o nível das companhias dos demais países. A surpresa foram as companhias australianas que ficaram em segundo lugar.

Tabela 3 Resultados do teste $\mathrm{H}$ por tipo de informação

\begin{tabular}{l|l}
\hline \multicolumn{2}{l}{ Estatística do Teste H } \\
\hline Categoria de Informações & Chi-Quadrado \\
\hline (I) Indicadores de Desempenho Ambiental & 0,451327 \\
\hline (II) Gastos ou Investimentos Ambientais & $19,135128^{*}$ \\
\hline (III) Litígios e Processos Ambientais & $66,063478^{*}$ \\
\hline (IV) Estrutrura de Governança e Adaptação do Sistema Administrativo & $14,221029^{*}$ \\
\hline (V) Credibilidade das Potíticas Ambientais & $7,726356^{* *}$ \\
\hline Total dos Itens Quantitativos & $18,516531^{*}$ \\
\hline (VI) Visão e Estratégia & $15,561125^{*}$ \\
\hline (VII) Perfil Ambiental & $76,141772^{*}$ \\
\hline (VIII) Iniciativas Ambientais Genéricas & 3,391955 \\
\hline Total dos Itens Qualitativos & $42,600622^{*}$ \\
\hline (IX) Informações Ambientais no Sistema Contábil da Empresa & $51,107803^{*}$ \\
\hline Total Geral & $33,408223^{*}$ \\
\hline
\end{tabular}

* Significativo a $1 \%$

** Significativo a $10 \%$

Por fim, na Tabela 3, constam os resultados do teste $\mathrm{H}$ por categoria de informação evidenciada. Da mesma forma que o ranking de informações, os resultados do teste $\mathrm{H}$ refletiram que as diferenças são mais signifi- cativas nos itens mais regulamentados. Nos itens I e VIII, que não são obrigatórios em nenhum dos marcos regulatórios analisados, os níveis de evidenciação apresentados pelas companhias da amostra não apresentam dife- 
renças significativas. Já nos demais itens que constam nas normas analisadas, as diferenças se mostraram significativas. $\mathrm{O}$ item $\mathrm{V}$ pode ser considerado um meio termo, pois não apresentou uma diferença tão grande como os demais, mas isso pode ser decorrente do impacto dos regulamentos norte-americano e, principalmente, ingleses sobre tal informação. Na Tabela 2, esse item aparece mais evidenciado pelas companhias norte-americanas e inglesas. De maneira geral, as diferenças, também, se mostraram significativas, assim como para os totais de informações quantitativas, descritivas e informações constantes nas demonstrações contábeis.

$\mathrm{O}$ que se pode concluir com base na Tabela 3 é que existem diferenças significativas entre os níveis de evidenciação ambiental das companhias analisadas e que essas diferenças estão presentes apenas nos itens mais regulamentados. Os resultados do teste demonstram que o nível de evidenciação de informações ambientais das companhias de petróleo analisadas reage aos estímulos regulatórios de seu país de origem. O que comprova a eficácia da implantação de instrumentos regulatórios com a finalidade de aumentar a transparência ambiental, isto é, a quantidade de informações ambientais divulgadas pelas companhias. Em termos estatísticos os resultados foram bastante coerentes. As diferenças significativas concentraram-se nas informações mais regulamentadas. Nas informações com baixo nível de obrigatoriedade, como os itens I, V e VIII, não ocorreram diferenças muito significativas.

\section{CONSIDERAÇÕES FINAIS}

Algumas considerações finais podem ser desenhadas com base no que foi apresentado na análise dos resultados. Em primeiro lugar, existem grandes diferenças de conteúdo, extensão e enforcement entre os regulamentos de disclosure ambiental dos países analisados. Ao examinar com profundidade os marcos regulatórios ambientais, notou-se que os EUA apresentam a moldura regulatória mais extensa e com mecanismos de fiscalização e coerção mais rígidos, o que pode ter influenciado o nível de compliance e, consequentemente, o maior nível de EAC das suas companhias analisadas. Em segundo lugar, os resultados dos dados coletados nos relatórios anuais mostraram-se coerentes com os níveis de regulamentação de cada país. As companhias norte-americanas divulgaram mais informações dos Itens VII, II e III, todos eles com conteúdo ambiental obrigatório. Nos demais países, o Item VII, também, foi o mais divulgado, sendo que ele continha a maioria das informações ambientais obrigatórias.

Uma tendência que foi observada na análise dos marcos regulatórios é o gradual au- mento da quantidade de legislação que rege o disclosure ambiental das companhias abertas nesses países. Esse aspecto ficou refletido nas datas de homologação das normas que regem o assunto. Com exceção dos EUA, os demais países apresentaram normas relativamente novas, homologadas nos últimos 10 anos, o que é um indício de que a demanda por tais informações não está sendo atendida de forma voluntária, insurgindo a necessidade regulatória.

Cabe ressaltar que este trabalho não teve a pretensão de apontar as vantagens ou desvantagens da regulação das práticas de evidenciação ambiental. Isso somente poderia ser obtido mediante uma análise qualitativa mais aprofundada dos resultados do estudo, o que devido ao curto espaço para exposição das ideias não foi possível fazer neste trabalho. Essa pesquisa mostra, contudo, que o disclosure ambiental das companhias analisadas é afetado pelos regulamentos de seus países de origem, comprovando, assim, que a normatização pode servir de estímulo para as práticas de evidenciação ambiental e que os seus efeitos não 
são simplesmente suplantados pelo voluntarismo pregado pela teoria do stakeholders. Para as próximas pesquisas o papel da regulamentação pode ser analisado com maior profundidade para determinar se ela é benéfica ou não às práticas de evidenciação ambiental.

\section{Referências}

Accounting Standards Board - ASB. Financial Reporting Standard, n. 12, Provisions, Contingent Liabilities and Contingent Assets, 1998.

ADAMS, C. A. The ethical, social and environmental reporting-performance portrayal gap. Accounting, Auditing \& Accountability Journal, v. 17, n. 5, p. 731-757, 2004.

ADAMS, C. A.; HILL, W.; ROBERTS, C. B. Corporate social reporting practices in western Europe: legitimating corporate behavior. British Accounting Review, v. 30, p. 1-21, 1998.

AERTS, W.; CORMIER, D.; MAGNAN, M. Intraindustry imitation in corporate environmental reporting: an international perspective. Journal of Accounting and Public Policy, v. 25, p. 299-331, 2006.

ALBERTA. S. Act, 1995. Disponível em: <http://www. qp.alberta.ca/574.cfm?page $=$ s04.cfm\&leg_type $=$ Acts\&isb $\mathrm{ncln}=9780779738106>$. Acesso em: 20 fev. 2009.

ALCIATORE, M.; DEE, C. C.; EASTON, P. Changes in environmental regulation and reporting: the case of the petroleum industry from 1989 to 1998 . Journal of Accounting and Public Policy, v. 23, p. 295-304, 2004. AICPA - American Institute of Certified Public Accountants. SOP - Statement of Position. Environmental Remediation Liabilities, 96-1, 1996.

AUSTRALIA. Australia Securities and Investments Commission Act, 2001. Disponível em: <http://www. austlii.edu.au/au/legis/cth/consol_act/asaica2001529/>. Acesso em: 25 mar. 2009.

Corporations Act, 2001. Disponível em: <http:// www.comlaw.gov.au/ComLaw/Management.nsf/current/ bytitle/3B11B1FDA7FE3EF3CA256F7100071C8F>.

Acesso em: 25 mar. 2009.

AASB - Australian Accounting Standards Board. Noncurrent assets held for sale and discontinued operations. Accounting Standard, n. 5, 2008,. Disponível em: <http:// www.aasb.com.au/Home.aspx>. Acesso em: 25 mar. 2009.

. Provisions, contingent liabilities and contingent assets. Accouting Standard, n. 137, 2008. Disponível em: $<$ http://www.aasb.com.au/Home.aspx>. Acesso em: 25 mar. 2009.

. Property, plant and equipment. Accouting

Standard, n. 116, 2008. Disponível em: <http://www.aasb. com.au/Home.aspx>. Acesso em: 25 mar. 2009.

. Changes in existing decommissioning, restoration and similar liabilities. Compiled Interpretation, n. 1, 2007. Disponível em: <http://www. aasb.com.au/Home.aspx>. Acesso em: 25 mar. 2009. ASIC - Australian Securities and Investments Commission. New financial reporting and procedural requirements. Regulatory Guide, RG, n. 68, 2007. Disponível em: <http://www.asic.gov.au/asic/asic.nsf>. Acesso em: 25 mar. 2009.
BEETS, D. S.; SOUTHER, C. C. Corporate environmental reports: the need for standards and an environmental assurance service. Accounting Horizons, v. 13, n. 2, p. 129-145, 1999.

BESANKO, D. Performance versus design standards in the regulation of pollution. Journal of Public Economics, v. 34, p. $19-44,1987$.

BLACK, T. R. Doing quantitative research in the social sciences: an integrated approach to research design, measurement and statistics. London: SAGE Publications Ltd, 2005.

BOESSO, G.; KUMAR, K. Drivers of corporate voluntary disclosure: a framework and empirical evidence from Italy and the United States. Accounting, Auditing \& Accountability Journal, v. 20, n. 2, p. 269-296, 2007. BRAGA, P. J.; SALOTTI, B. M. Relação entre nível de disclosure ambiental e características corporativas de empresas no Brasil. In: CONGRESSO USP DE CONTROLADORIA E CONTABILIDADE, 8., 2008, São Paulo. Anais... São Paulo: FEA/USP, 2008. CD-ROOM. BUHR, N. Histories of and rationales for sustainability reporting. In: UNERMAN, J.; BEBBINGTON, J.; O'DWYER, B. (Ed.). Sustainability, Accounting and Accountability. New York: Routledge, 2007.

; FREEDMAN, M. A comparison of mandated and voluntary environmental disclosure: the case of canada and united states. Critical Perspectives in Accounting Conference. New York, 1996. . Culture, institucional factors and differences in environmental disclosure between Canada and the United States. Critical Perspectives on Accounting, v. 12, p. 293-322, 2001.

CANADA. Bussines Corporations Act, 1985. Disponível em: <http://www.ic.gc.ca/eic/site/cd-dgc.nsf/eng/h_ cs02144.html>. Acesso em: 10 set. 2008.

. Canadian Environmental Protection Act, 1999

Disponível em: <http://www.ec.gc.ca/CEPARegistry/ the_act/>. Acesso em: 10 set. 2008.

CSA - Canadian Securities Administrators. Continuos disclosure obligations. National Instrument, p. 51102, 2008. Disponível em: <http://www.osc.gov. on.ca/Regulation/Rulemaking/Current/Part5/ rule_20040402_51-102-cont-disc-ob.pdf >. Acesso em: 20 fev. 2009.

CLARKSON, P. M.; LI, Y.; RICHARDSON, G. D.; VASVARI, F. P. Revisiting the relation between environmental performance and environmental disclosure: an empirical analysis. Accounting, Organizations and Society, v. 33, p. 303-327, 2008. COOPER, C. The non and nom of accounting for (m) other nature. Accounting, Auditing \& Accountability Journal, v. 5, n. 3, p. 16-39, 1992.

CORMIER, D.; GORDON, I. M. An examination 
of social and environmental reporting strategies.

Accounting, Auditing \& Accountability Journal, v. 14, n. 5, p. 587-616, 2001.

; MAGNAN, M.; VELTHOVEN, Van B.

Environmental disclosure quality in large german companies: economic incentives. Public Pressure or Institutional Conditions? European Accounting Review, v. 14, n. 1, p. 3-39, 2005.

COSTA, R. S.; MARION, J. C. A uniformidade na evidenciação das informações ambientais. Revista Contabilidade \& Finanças - USP, n. 43, p. 20-33, jan./ abr. 2007.

COWAN, S.; GADENNE, D. Australian corporate environmental reporting: a comparative analysis of disclosure practices across voluntary and mandatory disclosure systems. Journal of Accounting \& Organizational Change, n. 1, v. 2, p. 165-179, 2005. DEEGAN, C.; GORDON, B. A study of the environmental disclosures practices of Australian corporations. Accounting and Business Research, p. 187199, 1996.

; RANKIN, M. Do Australian companies report environmental news objectively? an analysis of environmental disclosures by firms prosecuted successfully by the Environmental Protection Authority. Accounting, Auditing \& Accountability Journal, v. 9, n. 2, p. 50-67, 1996.

DYE, R. A. Disclosure of non-proprietary information. Journal of Accounting Research, v. 8, p. 135-155, 1985. ENGLAND. Companies Act, 2006. Disponível em: <http://www.opsi.gov.uk>. Acesso em: 15 nov. 2008. EPSTEIN, M. J.; FREEDMAN, M. Social disclosure and the individual investor. Accounting, Auditing \& Accountability Journal, v. 7, n. 4, p. 94-109, 1994. FASB - Financial Accounting Standards Board. Capitalization of Costs to Treat Environmental Contamination. Emerging Issues Task Force - EITF, v. 8, n. 90, 1990.

Accounting for the cost of asbestos removal.

Emerging Issues Task Force - EITF, n. 89, v. 3, 1989.

. The treatment of certain site restoration/

environmental exit costs when testing a long-lived asset for impairment. Emerging Issues Task Force - EITF, n. 95, v. 23, 1995.

Accounting for asset retirement obligations.

Statement of Financial Accounting Standards, n. 143, 2001. FSA - Financial Services Authority. FSA Handbook, 2009. Disponível em: <http://www.fsa.gov.uk/>. Acesso em: 20 out. 2008.

FLEISCHMAN, R. K.; SCHUELE, K. Green accounting: a primer. Journal of Accounting Education, n. 24, p. 35-66, 2006.

FREEDMAN, M.; STAGLIANO, A. J. Some new evidence on the effectiveness of authoritative environmental reporting guidance. Advances in Public Interest Accounting, v. 13, p. 1-15, 2007.

; WASLEY, C. The association between

environmental performance and environmental disclosure in annual reports and $10 \mathrm{~K}$. Advances in Public Interest Accounting, v. 3, p. 183-193, 1990.

FROST, G. R. The introduction of mandatory environmental reporting guidelines: Australian evidence. ABACUS, v. 43, n. 2, 2007.

GALLHOFER, S.; HASLAM, J. The direction of green accounting policy: critical reflections. Accounting, Auditing \& Accountability Journal, v. 10, Iss. 2, p. 148174, 1997.

GAMBLE, G. O.; HSU, K.; JACKSON, C.; TOLLERSON, C. D. Environmental disclosures in annual reports: an international perspective. The International Journal of Accounting, v. 31, n. 3, p. 293-331, 1996.

GAO, S. S.; HERAVI, S.; XIAO, J. Z. Determinants of corporate social and environmental reporting in Hong Kong: a research note. Accounting Forum, v. 29, p. 233 242, 2005.

GRI - Global Reporting Initiative. About GRI, 2009. Disponível em: <http://www.globalreporting.org/ AboutGRI/>. Acesso em: 25 mar. 2009.

GRAY, R.; BEBBINGTON, J. Accounting for the environment. 2 ed. London: Sage, 2001.

; JAVAD, M.; POWER, D. M.; SINCLAIR, C.

D. Social and environmental disclosure and corporate characteristics: a research note and extention. Journal of Business Finance \& Accounting, n. 28, v. 3; 4, Apr./May 2001. ; OWEN, D.; ADAMS, C. Accounting \&

accountability: changes and challenges in corporate social and environmental reporting. Londres: Prentice Hall Europe, 1996.

GUNNINGHAM, N.; GRABOSKY, P.; SINCLAIR, D. Smart regulation: designing environmental policy. New York: Oxford University Press Inc., 1998.

GUTHRIE, J.; CUGANESAN, S.; WARD, L. Industry specific social and environmental reporting: the Australian food and beverage industry. Accounting Forum, v. 32, p. 1-15, 2008.

HACKSTON, D.; MILNE, M. J. Some determinants of social and environmental disclosures in New Zealand companies. Accounting, Auditing \& Accountability Journal, v. 9, n. 1, p. 77-108, 1996.

HALME, M.; HUSE, M. The influence of corporate governance, industry and country factors on environmental reporting. Scandinavian Journal of Management, v. 13, n. 2, p. 137-157, 1997.

HART, P. E.; OULTON, N. Growth and size of firms. The Economic Journal, v. 106, n. 438, p. 1242-1252, Sep. 1996. HARTE, G.; OWEN, D. Environmental disclosures in the annual reports of british companies: a research note. Accounting, Auditing \& Accountability Journal, v. 4, n. 3, p. 51-61, 1991

HOLGAARD, J. E.; JORGENSEN, T. H. A decade of mandatory environmental reporting in denmark. European Environment, v. 15, p. 362-373, 2005.

HOLLAND, L.; FOO, B. Y. Differences in environmental reporting practices in the UK and the US: the legal and regulatory context. The British Accounting Review, v. 35, p. 1-18, 2003.

IIIEE - International Institute for Industrial

Environmental Economics. Corporate environmental reporting: review of policy action in Europe. Lund University. 2002. Disponível em: <www.iiiee.lu.se>. Acesso em: 24 ago. 2007.

ISLAM, M. A.; DEEGAN, C. Motivations for an 
organization within a developing country to report social responsibility information: evidence from Bangladesh.

Accounting, Auditing \& Accountability Journal, v. 21, n. 6, p. 850-874, 2008.

JORGENSEN, B. N.; SODERSTROM, N. S.

Environmental disclosures within legal and accounting contexts an international perspective. Columbia business school / Chazen Web Journal, n. 15, 2007.

KPMG - International and sustainability ltd. KPMG International survey of corporate responsibility reporting 2005. London: 2005. Disponível em: <www.kpmg.nl/ sustainability.com>. Acesso em: 03 jun. 2008. ; UNEP - United Nations Environment Programme. Carrots and sticks for starters: current trends and approaches in voluntary and mandatory standards for sustainability reporting. London: 2006. Disponível em: <www.kpmg.nl/sustainability.com>. Acesso em: 03 jun. 2008.

LARRINAGA, C.; CARRASCO, F.; CORREA, C.; LLENA, F., MONEVA, J. M. Accountability and accounting regulation: the case of the spanish environmental disclosure standard. The European Accounting Review, v. 11, n. 4, p. 723-740, 2002. LOPES, A. B. A informação contábil e o mercado de capitais. São Paulo: Pioneira Thomson Learning, 2002. MAUNDERS, K. T.; BURRITT, R. L. Accounting and Ecological Crisis. Accounting, Auditing \& Accountability Journal, v. 4, n. 3, p. 9-26, 1991.

MEDLEY, P. Environmental accounting - what does it mean to professional accountants? Accounting, Auditing \& Accountability Journal, v. 10, n. 4, p. 594-600, 1997. MURCIA, F.; SANTOS, A.; SOUZA, F. C. Social and environmental disclosure practices of Brazilian companies. International Accounting Congress, IAEER e ANPCONT, 2009.

NOBES, C.; PARKER, R. Comparative international accounting. 10. ed. Cambrige: Printice Hall, 2008.

NYQUIST, S. The legislation of environmental disclosure in three nordic contries - a comparison. Business Strategy and the Environment, v. 12, p. 12-25, 2003.

POWER, M. Auditing and environmental expertise: between protest and professionalization. Accounting, Auditing \& Accountability Journal, v. 4, n. 3, p. 30-42, 1991.

REPETTO, R.; MACSKIMMING, A.; ISUNZA, G. C. Environmental disclosure requirements in the securities regulations and financial accounting standards of Canada, Mexico and the United States. Commission for Environmental Cooperation, 2002. Disponível em: <www. cec.org>. Acesso em: 10 maio 2008.

RIBEIRO, A. M.; BELLEN, H. M. Van. Evidenciação ambiental: uma comparação entre os relatórios de empresas brasileiras. In: CONGRESSO USP DE CONTROLADORIA E CONTABILIDADE, 8., 2008, São Paulo. Anais... São Paulo: FEA/USP, 2008. CD-ROOM. ROBERTS, C. B. Environmental disclosures: a note on reporting practices in mainland Europe. Accounting, Auditing \& Accountability Journal, v. 4, n. 3, p. 62-71, 1991.

ROVER, S.; TOMAZZIA, E. C.; MURCIA, F.; BORBA J. A. Explicações para a divulgação voluntária ambiental no Brasil utilizando análise de regressão em painel. International Accounting Congress, IAEER e ANPCONT, 2009.

SCOTT, W. R. Financial Accounting Theory. 3. ed. Toronto: Penson Education Canada Inc. 2003. SEC - Securities and Exchange Commission. Staff Accounting Bulletin - SAB, n. 92, 1993. Disponível em: <http://www.sec.gov/rules/>. Acesso em: 10 out. 2008. SIEGEL, S.; CASTELLAN, J. N. Jr. Estatística nãoparamétrica para ciências do comportamento. 2. ed. Porto Alegre: Artmed. 2006.

SKILLIUS, A.; WENNBERG, U. Continuity, credibility and comparability: key challenges for corporate environmental performance measurement and communication. The International Institute for Industrial Environmental Economics at Lund University. 1998.

Disponível em: <http://reports.eea.europa.eu/ESS09/en/ ccc.pdf $>$. Acesso em: 20 jan. 2008.

TROTMAN, K. T.; BRADLEY, G. W. Association between social responsibility disclosure and characteristics of companies. Accounting, Organizations and Society, v. 6, n. 4, p. 355-362, 1981.

UNERMAN, J.; BEBBINGTON, J.; O'DWYER, B. (Eds.). Sustainability, Accounting and Accountability. New York: Routledge, 2007.

USA - UNITED STATES OF AMERICA. Code of Federal Regulation - CFR. Disponível em: <http://www. gpoaccess.gov/index.html>. Acesso em: 10 nov. 2008 . USA - UNITED STATES OF AMERICA. Environmental Protection Agency - EPA. Comprehensive Environmental Response, Compensation and Liability Act - CERCLA. 2006. Disponível em: <http://www.epa.gov/>. Acesso em: 10 out. 2008.

WISEMAN, J. An evaluation of environmental disclosures made in corporate annual reports. Accounting, Organization and Society, v. 7, n. 1, p. 553 563, 1982.

ZERK, J. A. Multinationals and corporate social responsibility: Limitations and Opportunities in International Law. Cambridge: Cambridge University Press, 2006 